\title{
KARL MARX, "PARA A CRÍTICA DA ECONOMIA POLÍTICA”, PRIMEIRO FASCÍCULO, BERLIN, FRANZ DUNCKER, 1859 ${ }^{1}$
}

\author{
Friedrich Engels \\ 15 de Agosto de 1859
}

\begin{abstract}
$I$
Em todos os domínios científicos, desde há muito os alemães demonstraram que estão ao nível das restantes nações civilizadas e, na maior parte deles, que são superiores. Apenas uma ciência não contava com qualquer nome alemão entre os seus corifeus: a Economia Política. A razão é evidente. A Economia Política é a análise teórica da sociedade burguesa moderna e pressupõe, portanto, condições burguesas desenvolvidas, que, na Alemanha, desde as guerras da Reforma e dos Camponeses e, sobretudo, desde a Guerra dos Trinta Anos, não se puderam estabelecer durante séculos. A separação da Holanda do Império afastou a Alemanha do comércio mundial e reduziu de antemão o seu desenvolvimento industrial às proporções mais mesquinhas; e enquanto os alemães recuperavam tão penosa e lentamente das devastações das guerras civis, enquanto empregavam toda a sua energia cívica - que nunca foi muito grande - na luta estéril contra as barreiras alfandegárias e os regulamentos comerciais loucos que cada príncipe em formato reduzido e cada pequeno barão do Império impunham à indústria dos seus súbditos, enquanto as cidades do Império entravam na decadência dos grêmios e do patriciado, enquanto tudo isso se passava, a Holanda, a Inglaterra e a França conquistavam os primeiros lugares no comércio mundial, estabeleciam colônia atrás de colônia e desenvolviam a indústria manufatureira ao mais alto grau, até que, finalmente, a Inglaterra, por meio do vapor, que só então deu valor às suas jazidas de carvão e de ferro, acedeu ao cume do desenvolvimento burguês moderno. Enquanto, porém, foi preciso conduzir uma luta contra uns restos tão ridiculamente antiquados da Idade Média como aqueles que entravaram até $1830 \mathrm{o}$ desenvolvimento burguês material da Alemanha, nenhuma Economia Política alemã foi possível. Somente com o estabelecimento do Zolverein ficaram os alemães em situação de poderem quando muito apenas entender a Economia Política. A partir desse tempo, começou de fato a importação da Economia inglesa e francesa para proveito da burguesia alemã. Em breve os círculos científicos e a burocracia se apoderaram da matéria importada e trabalharam-na de uma maneira não muito digna do crédito do "espírito alemão". Da mistura de cavaleiros de indústria literatos, de comerciantes, pedantes e burocratas, gerou-se, então, uma literatura econômica alemã que, quanto à sensaboria, falta de profundidade e de ideias, prolixidade e plágio, só tem par no romance alemão. Entre as pessoas com objetivos práticos, desenvolveu-se primeiro a escola protecionista dos industriais, cuja autoridade, List, foi ainda o melhor que a literatura econômica burguesa alemã produziu, apesar de toda a sua obra gloriosa ter sido copiada do francês Ferrier, criador teórico do sistema continental. Face a esta orientação, formou-se, nos anos quarenta, a escola do livre-
\end{abstract}


cambismo dos comerciantes nas províncias do Báltico, que papaguearam os argumentos dos free-traders, ingleses com uma fé pueril, mas interessada. Por fim, entre os pedantes e burocratas que tiveram de ocupar-se do lado teórico da disciplina, havia áridos colecionadores de herbários sem crítica, como o senhor Rau, especuladores que a armar ao esperto traduziam as proposições estrangeiras num Hegeliano mal digerido, como o senhor Stein ou respigadores beletriantes no domínio "histórico-cultural", como o senhor Riehl. O que acabou por sair daqui foi a Cameralística, um purê de toda a espécie de coisas estranhas, regado com um molho econômico eclético, do tipo que um licenciado em direito precisa saber para o exame de Estado.

Enquanto, deste modo, a burguesia, o pedantismo acadêmico e a burocracia, na Alemanha, ainda tinham dificuldade em aprender de cor e em clarificar em alguma medida os primeiros elementos da economia anglo-francesa como dogmas intangíveis, fazia a sua aparição o partido proletário alemão. Toda a sua existência teórica resultava do estudo da Economia Política e do instante do seu aparecimento data também a Economia alemã científica, autônoma. Esta Economia alemã repousa essencialmente sobre a concepscão materialista da história, cujos traços fundamentais são expostos brevemente no prefácio da obra atrás citada. Quanto ao principal, este prefácio foi já reproduzido em Das Volk, pelo que para ele remetemos. Não apenas para a Economia, mas para todas as ciências históricas (e são históricas todas as ciências que não são ciências da natureza), foi uma descoberta revolucionária esta proposição: “O modo de produção da vida material é que condiciona o processo da vida social, política e espiritual"; todas as relações sociais e do Estado, todos os sistemas religiosos e jurídicos, todas as visões teóricas, que emergem na história, só podem, então, ser compreendidas se as condições de vida materiais da época correspondente forem compreendidas e se as primeiras forem derivadas destas condições materiais. "Não é a consciência dos homens que determina o seu ser, mas, inversamente, o seu ser social que determina a sua consciência.”. A proposição é tão simples que teria de ser evidente para quem não esteja preso nas malhas do logro idealista. A coisa tem, porém, as mais altas consequências revolucionárias, não apenas para a teoria, mas também para a prática: "Numa certa etapa do seu desenvolvimento, as forças produtivas materiais da sociedade entram em contradição com as relações de produção existentes ou, o que é apenas uma expressão jurídica delas, com as relações de propriedade no seio das quais se tinham até aí movido. De formas de desenvolvimento das forças produtivas, estas relações transformam-se em grilhões das mesmas. Ocorre então uma época de revolução social. Com a transformação do fundamento econômico revoluciona-se, mais devagar ou mais depressa, toda a imensa superestrutura. [...] As relações de produção burguesas são a última forma antagônica do processo social da produção, antagônica não no sentido de um antagonismo individual, mas de um antagonismo que decorre das condições sociais de vida dos indivíduos; mas as forças produtivas que se desenvolvem no seio da sociedade burguesa criam, ao mesmo tempo, as condições materiais para a resolução deste antagonismo.”. A perspectiva de uma poderosa revolução, da revolução mais poderosa de todos os tempos, abre-se, portanto, perante nós, desde logo, com a prossecução da nossa tese materialista e com a sua aplicação ao presente.

Considerando, porém, as coisas mais de perto, verifica-se também que a proposição de aparência tão simples como a de que a consciência dos homens depende do seu ser e não inversamente 
contunde diretamente, logo nas suas primeiras consequências, todo o idealismo, mesmo o mais dissimulado. Todas as visões tradicionais e habituais acerca de tudo o que é histórico são por ela negadas. Todo o modo tradicional do raciocínio político cai por terra; toda a patriótica nobreza de alma se levanta indignada contra uma concepção tão desprovida de caráter. A nova maneira de ver choca, portanto, necessariamente, não apenas os representantes da burguesia, mas também a massa dos socialistas franceses que querem levantar o mundo dos gonzos com a fórmula mágica liberte, égalité, fraternité. Causou, porém, o mais consumado furor entre os vociferadores democratas vulgares alemães. Apesar disso, procuraram de preferência explorar as novas ideias, plagiando-as, embora com rara incompreensão.

O desenvolvimento da concepção materialista, mesmo sobre um único exemplo histórico, era um trabalho científico que teria exigido um estudo tranquilo durante anos, pois é evidente que, nesta matéria, nada se pode fazer com simples frases, que só um material histórico em massa, criticamente considerado e completamente dominado, pode habilitar para a solução de uma tal tarefa. A revolução de Fevereiro lançou o nosso partido na cena política e tornou-lhe, assim, impossível a prossecução de fins puramente científicos. Apesar disso, essa visão fundamental atravessa como fio condutor todas as produções literárias do partido. Em todas elas, em cada caso sempre se prova como a ação todas as vezes brotou de impulsos materiais diretos, e não das frases que os acompanhavam e como, pelo contrário, as frases políticas e jurídicas saíram dos impulsos materiais tal como a ação política e os seus resultados.

Quando, depois da derrota da revolução de 1848/1849, houve um momento em que a ação sobre a Alemanha a partir do estrangeiro se tornava cada vez mais impossível, o nosso partido abandonou o terreno das disputas de emigração - pois essa era a única ação possível — à democracia vulgar. Enquanto esta se agitava à saciedade, andando hoje à pancada para amanhã confraternizar e depois de amanhã, novamente, lavar toda a roupa suja diante de toda a gente, enquanto ela ia por toda a América pedir esmola para, logo de seguida, armar um novo escândalo acerca da repartição dos tostões apanhados - o nosso partido ficou contente por, de novo, encontrar alguma calma para estudar. Tinha a grande vantagem de ter uma nova visão científica como base teórica, cuja elaboração lhe dava suficientemente que fazer; logo, por isso, nunca podia descer tão baixo como os "grandes homens" da emigração.

O primeiro fruto desses estudos é o livro que temos diante de nós.

\section{II}

Num escrito como este não se pode tratar de uma mera crítica desultória de capítulos isolados da Economia, do tratamento separado desta ou daquela questão econômica polêmica. Ele visa antes, desde logo, uma visão de conjunto sistemática de todo o complexo da ciência econômica, um desenvolvimento coerente das leis da produção burguesa e da troca burguesa. Como os economistas não são mais do que os intérpretes e os apologistas destas leis, este desenvolvimento é, ao mesmo tempo, a crítica de toda a literatura econômica.

Desde a morte de Hegel, quase nenhuma tentativa foi feita para desenvolver uma ciência no seu próprio encadeamento interno. Da dialética do mestre, a escola hegeliana oficial tinha se apropriado 
apenas da manipulação dos artifícios mais simples, que aplicava a toda e qualquer coisa e, frequentemente ainda, com uma ridícula falta de jeito. Todo o legado de Hegel se limitava, para ela, a um puro chavão, com a ajuda do qual cada tema era construído de uma forma apropriada, e a um índice de palavras e de maneiras de dizer que não tinham qualquer outro fim do que estarem presentes no momento certo em que as ideias e os conhecimentos positivos faltassem. Aconteceu, assim, que, tal como um professor de Bona disse, estes hegelianos não percebiam nada de nada, mas podiam escrever sobre tudo. E certamente assim era. No entanto, estes senhores, apesar da sua suficiência, tinham, contudo, uma tal consciência da sua debilidade que se mantinham o mais possível afastados das grandes tarefas; a velha e antiquada ciência conservava o seu terreno, em virtude da sua superioridade em saber positivo; e só quando Feuerbach despediu o conceito especulativo é que a hegelianice se foi gradualmente apagando e pareceu que o império da velha metafísica com as suas categorias fixas tinha começado de novo na ciência.

A coisa tinha o seu fundamento natural. Ao regime dos Diádocos de Hegel que se tinha perdido em pura fraseologia, seguia-se naturalmente uma época em que o conteúdo positivo da ciência prevalecia de novo sobre o seu lado formal. A Alemanha, porém, lançava-se também ao mesmo tempo com uma energia deveras extraordinária para as ciências da natureza, correspondendo ao poderoso desenvolvimento burguês desde 1848. E, com o tornar-se moda destas ciências, em que a tendência especulativa nunca tinha alcançado qualquer valor significativo, a velha maneira metafísica de pensar, inclusive a banalidade wollfiana mais extrema, propagou-se de novo. Hegel tinha desaparecido, desenvolvera-se o novo materialismo das ciências da natureza que, teoricamente, em quase nada se distingue do século XVIII e que, na maioria dos casos, só tem a vantagem de um material científiconatural mais rico, designadamente químico e fisiológico. Reproduzido até a mais extrema banalidade, encontramos o tacanho modo de pensar filisteu do período pré-kantiano de Büchner e de Vogt, e mesmo de Moleschott, que jura por Feuerbach e a cada instante se perde, do modo mais divertido, entre as categorias mais simples. A pileca ancilosada do entendimento quotidiano burguês estaca naturalmente embaraçada perante o fosso que separa a essência do fenômeno, a causa do efeito; mas, quando se vai à caça, a cavalo com galgos, no terreno muito acidentado do pensamento abstrato, precisamente, de modo algum, se pode montar uma pileca.

Havia, portanto, aqui uma outra questão para resolver, que não tinha nada a ver com a Economia Política em si. Como tratar da ciência? De um lado, encontrava-se a dialética de Hegel, na forma "especulativa", completamente abstrata, em que Hegel a tinha deixado; do outro lado, o método ordinário, essencialmente metafísico-wollfiano, agora novamente na moda, segundo o qual os economistas burgueses tinham escrito os seus grossos livros falhos de coerência. Este último tinha sido de tal modo teoricamente aniquilado por Kant e, sobretudo, por Hegel, que só a inércia e a falta de um outro método simples puderam tornar possível a sua persistência prática. Por outro lado, na sua forma presente, o método de Hegel era absolutamente inutilizável. Ele era essencialmente idealista, e aqui se tratava de desenvolver uma visão do mundo que era mais materialista do que todas as anteriores. Ele partia do pensamento puro, e aqui devia partir-se dos fatos mais obstinados. Um método que, segundo o seu próprio testemunho, "de nada através de nada chegava a nada", não estava, nesta [sua] forma, de modo algum, no lugar [certo]. 
Apesar disso, dentre todo o material lógico atual, era o único fragmento a que ao menos se podia ligar. Não tinha sido criticado, não tinha sido superado; nenhum dos adversários do grande dialético tinha podido abrir uma brecha no seu glorioso edifício; tinha desaparecido, porque a escola de Hegel não tinha sabido agarrá-lo. Antes do mais, tratava-se, portanto, de submeter o método de Hegel a uma crítica eficaz.

O que distinguia o modo de pensar de Hegel do de todos os outros filósofos era o enorme sentido histórico que lhe estava subjacente. Por abstrata e idealista que fosse a forma, o desenvolvimento do seu pensamento não deixava de ir sempre em paralelo com o desenvolvimento da história universal, e esta última, propriamente, não deverá ser senão a prova do primeiro. Ainda que, por este fato, a relação correta tenha sido também invertida e posta de pernas para o ar, o seu conteúdo real penetrou, contudo, por todo o lado, na filosofia; tanto mais que Hegel se diferenciava dos seus discípulos em que não se gabava, como eles, da sua ignorância, mas era uma das cabeças mais sábias de todos os tempos. Foi ele o primeiro a procurar mostrar um desenvolvimento, um encadeamento interno, na história e, por estranhas que agora muitas coisas na sua filosofia da história nos possa parecer, a grandiosidade da própria visão fundamental é ainda hoje digna de admiração, quando se lhe comparam os seus predecessores ou mesmo aqueles que depois dele se permitiram reflexões universais sobre a história. Na Fenomenologia, na Estética, na História da Filosofia, por toda a parte perpassa essa grandiosa concepção da história e, por toda a parte, a matéria é tratada historicamente, numa conexão determinada, ainda que também abstratamente distorcida, com a história.

Essa concepção da história que fez época foi o pressuposto teórico direto da nova visão materialista e, já por este fato, fornecia também um ponto de partida para o método lógico. Se esta dialética desaparecida, a partir da posição do "pensamento puro", tinha conduzido já a semelhantes resultados, se, além disso, tinha acabado, como que a brincar, com toda a lógica e a metafísica anteriores, tinha em todo o caso de haver nela mais do que sofística e bizantinice. Mas a crítica deste método, perante a qual toda a filosofia oficial tinha recuado e recua ainda, não era coisa de pouca monta.

Marx era, e é, o único que podia entregar-se ao trabalho de tirar da casca da lógica hegeliana o núcleo que encerra as descobertas reais de Hegel neste domínio e de restabelecer o método dialético, despido das suas roupagens idealistas, na forma simples em que ele se torna a única forma correta de desenvolvimento do pensamento. Consideramos a elaboração do método que está na base da crítica de Marx à Economia Política como um resultado que, pelo seu significado, em quase nada é inferior à visão materialista fundamental.

Mesmo depois de adquirido o método, a crítica da Economia podia ainda ser abordada de duas maneiras: historicamente ou logicamente. Como na história, tal como no seu reflexo literário, o desenvolvimento, a traços largos, progride das relações mais simples para as mais complicadas, o desenvolvimento histórico-literário da Economia Política fornecia um fio condutor natural a que a crítica se podia ligar e, a traços largos, as categorias econômicas apareceriam na mesma ordem do que o desenvolvimento lógico. Esta forma tem aparentemente a vantagem de uma maior clareza, pois, assim, segue-se o desenvolvimento real; de fato, porém, no máximo tornar-se-ia apenas mais popular. A história procede frequentemente por saltos e em ziguezague e, se houvesse que segui-la ao mesmo tempo por toda 
a parte, teria não apenas de recolher muito material de pouca importância, como também o curso do pensamento teria frequentemente que ser interrompido; além disso, não se poderia escrever a história da economia sem a da sociedade burguesa e, deste modo, o trabalho tornar-se-ia infindável, uma vez que faltam os trabalhos preparatórios. Portanto, o modo lógico de tratamento era o único que estava no seu lugar. Este [modo], porém, não é de fato senão o histórico, despido apenas da forma histórica e das casualidades perturbadoras. Por onde esta história começa, por aí tem de começar igualmente o curso do pensamento, e o seu avanço ulterior não será mais do que o reflexo, numa forma abstrata e teoricamente consequente, do decurso histórico; um reflexo corrigido, mas corrigido segundo leis que o próprio decurso histórico real fornece, na medida em que cada momento pode ser considerado no ponto de desenvolvimento da sua plena maturidade, da sua forma clássica.

Com esse método, partimos da primeira e mais simples relação que historicamente, faticamente, nos apresenta - neste caso, portanto, da primeira relação econômica com que nos deparamos. Analisamos esta relação. Pelo fato de que é uma relação, acontece já que tem dois lados que se relacionam um com o outro. Cada um desses lados é considerado por si; decorre daí o modo do seu relacionamento mútuo, a sua ação recíproca. Dar-se-ão contradições que reclamam uma solução. Como, porém, não consideramos aqui um processo de pensamento abstrato, que se passa apenas na nossa cabeça, mas um processo real, que se passou realmente ou ainda se passa num tempo qualquer, tais contradições desenvolveram-se na prática e verossimilmente encontraram [ai] a sua solução. Seguiremos o modo dessa solução e verificaremos que foi causada pela produção de uma nova relação, cujos dois lados contrapostos teremos doravante que desenvolver, etc.

A Economia Política começa com a mercadoria, com o momento em que produtos são trocados por outros, quer por indivíduos quer por comunidades naturais. O produto que entra na troca é mercadoria. Ele só é, porém, mercadoria porque à coisa, ao produto, se liga uma relaşão entre duas pessoas ou comunidades, a relação entre o produtor e o consumidor, que aqui não mais se encontram unidos na mesma pessoa. Temos aqui, desde logo, um exemplo de um fato peculiar que perpassa toda a Economia e estabeleceu uma lamentável confusão na cabeça dos economistas burgueses: a Economia não trata de coisas, mas de relações entre pessoas e, em última instância, entre classes; essas relações estão, porém, sempre ligadas a coisas e aparecem como coisas. Esta conexão que, em casos isolados, este ou aquele economista, sem dúvida vislumbrou, descobriu-a Marx pela primeira vez no seu valor para toda a Economia e, por esse fato, tornou as questões mais difíceis de tal modo simples e claras que agora mesmo os economistas burgueses as poderão compreender.

Se considerarmos agora a mercadoria segundo os seus vários aspectos e, designadamente, a mercadoria tal como se desenvolveu completamente, e não tal como ela só penosamente se desenvolve no comércio de troca natural de duas comunidades primitivas, ela se apresenta a nós sob os dois pontos de vista de valor de uso e de valor de troca e entramos aqui, de pronto, no domínio do debate econômico. Quem quiser ter um exemplo flagrante de como o método dialético alemão, no seu estádio atual de formação, é superior ao antigo [método] metafísico, chão e politiqueiro, pelo menos tanto como os caminhos-de-ferro o são relativamente aos meios de transporte da Idade Média, leia, em Adam Smith ou 
em qualquer outro economista oficial de nomeada, que suplícios o valor de troca e o valor de uso causaram a estes senhores, como se torna para eles difícil distingui-los ordenadamente e apreender cada um deles na sua própria determinatez [Bestimmtheit], e faça a comparação com o desenvolvimento simples e claro de Marx.

Ora, uma vez desenvolvidos o valor de uso e o valor de troca, a mercadoria é apresentada como unidade imediata de ambos, tal como entra no processo de troca. As contradições que aqui se dão podem ser lidas nas páginas 20-21. Observamos apenas que essas contradições não têm só um interesse teórico, abstrato, mas que refletem, ao mesmo tempo, as dificuldades provenientes da natureza da relação de troca imediata, do comércio de troca simples, as impossibilidades a que necessariamente chega esta primeira forma grosseira de troca. A solução destas impossibilidades encontra-se no fato de a propriedade de representar o valor de troca de todas as outras mercadorias ser transpostada para uma mercadoria especial - o dinheiro. O dinheiro, ou a circulação simples, é, então, desenvolvido no segundo capítulo e, designadamente: 1. o dinheiro como medida dos valores, pelo que, então, o valor medido em dinheiro, o preço, recebe a sua determinação mais aproximada; 2. como meio de circulação, e 3. como unidade de ambas as determinações como dinheiro real, como representante de toda a riqueza material burguesa. Com isso, termina-se o desenvolvimento do primeiro fascículo, reservando o segundo para a passagem do dinheiro a capital.

Vê-se como com esse método o desenvolvimento lógico não precisa se manter no domínio puramente abstrato. Pelo contrário, ele requer a ilustração histórica, o contato contínuo com a realidade. Esses elementos de referência são inseridos, portanto, também com grande diversidade e, designadamente, tanto às alusões ao decurso histórico real em diferentes estádios do desenvolvimento social como à literatura econômica, em que, desde o princípio, se procura a elaboração clara das determinações das relações econômicas. A crítica dos modos singulares mais ou menos unilaterais ou confusos de conceber [a matéria], no essencial, está já dada, então, no próprio desenvolvimento lógico e pode ser brevemente exposta.

Num terceiro artigo, entraremos no conteúdo econômico do próprio livro.

\section{Notas:}

1 Extraído de Marxist Internet Arcbives (Secção em Português). Disponível em: http://www.marxists.org/portugues/marx/1859/08/15.htm Acesso em 07 de junho de 2009. Primeira Edição: Escrito por Engels de 3 a 15 de Agosto de 1859. Publicado no jornal Das Volk, n. 14 e 16 , de 6 e 20 de Agosto de 1859, respectivamente. Fonte: Obras Escolhidas em três tomos, Editorial "Avante!" Tradução: José BARATA-MOURA (Publicado segundo o texto do jornal. Traduzido do alemão). Transcrição e HTML: Fernando A. S. Araújo, agosto 2007. Direitos de Reprodução: (C) Direitos de tradução em língua portuguesa reservados por Editorial "Avante!" Edições Progresso Lisboa - Moscovo, 1982. 